\title{
Student and staff experiences of attendance monitoring in undergraduate obstetrics and gynecology: a cross-sectional survey
}

This article was published in the following Dove Press journal:

Advances in Medical Education and Practice

4 April 2016

Number of times this article has been viewed

\author{
Richard P Deane \\ Deirdre J Murphy \\ Department of Obstetrics and \\ Gynaecology, Trinity College Dublin, \\ The University of Dublin, Coombe \\ Women \& Infants University Hospital, \\ Dublin, Republic of Ireland
}

Background: Despite the widespread introduction of active learning strategies to engage students across modern medical curricula, student attendance and attendance monitoring remain a challenging issue for medical educators. In addition, there is little published evidence available to medical educators regarding the use of attendance monitoring systems. The aim of this study was to evaluate the opinions of students and staff about the use of a paper-based student logbook to record student attendance across all clinical and classroom-based learning activities within an undergraduate clinical rotation in obstetrics and gynecology (OBGYN).

Methods: Each student undertaking the clinical rotation in OBGYN was required to complete a paper-based logbook in a booklet format that listed every clinical and classroom-based activity that the student was expected to attend. A cross-sectional survey evaluating the acceptability, practicality, and effect on access to learning opportunities of using the logbook was undertaken. The survey was conducted among all medical students who completed their OBGYN rotation over a full academic year and staff who taught on the program.

Results: The response rate was $87 \%(n=128 / 147)$ among students and $80 \%(n=8 / 10)$ among staff. Monitoring attendance was widely acceptable to students $(n=107 / 128,84 \%)$ and staff $(\mathrm{n}=8 / 8,100 \%)$. Most students $(\mathrm{n}=95 / 128,74 \%)$ and staff $(\mathrm{n}=7 / 8,88 \%)$ recommended that attendance should be mandatory during rotations. Almost all staff felt that attendance should contribute toward academic credit ( $\mathrm{n}=7 / 8,88 \%)$, but students were divided $(\mathrm{n}=73 / 128,57 \%)$. Students $(n=94 / 128,73 \%)$ and staff $(n=6 / 8,75 \%)$ reported that the use of the logbook to record attendance with tutor signatures was a satisfactory system, although students questioned the need for recording attendance at every classroom-based activity. Most students felt that the logbook facilitated access to learning experiences during the rotation ( $n=90 / 128,71 \%)$. Staff felt that the process of signing logbooks improved their interaction with students $(n=6 / 8,75 \%)$. Conclusion: The survey showed that the use of a paper-based logbook to record medical student attendance with tutor signatures across all clinical and classroom-based learning activities was acceptable and practical for students and staff and was felt to facilitate access to learning opportunities. The study provides medical educators with evidence to support monitoring of attendance within clinical rotations.

Keywords: attendance, attendance monitoring, clinical learning environment, logbook, medical students, obstetrics and gynecology

\section{Introduction}

Student attendance is an important issue for both medical students and their educators. For medical students, attendance is an important factor in developing clinical competence with evidence that attendance during clinical rotations correlates positively 
with academic performance. ${ }^{1}$ For medical educators and schools, attendance is important in order to optimize the use of limited and expensive resources, to account to regulatory bodies for the training and performance of students who qualify from their medical degree courses, and as a marker of student professionalism. ${ }^{2-5}$ For these reasons, medical schools are challenged to monitor the attendance of their students. However, there is little evidence regarding the use of attendance monitoring systems during clinical rotations, particularly in the clinical learning environment. It is timely, therefore, to evaluate the experiences of medical schools using attendance monitoring systems.

The aim of this study was to evaluate the opinions of students and staff about the use of a paper-based student logbook in a booklet format to record student attendance across all clinical and classroom-based learning activities within an undergraduate clinical rotation in obstetrics and gynecology (OBGYN). The following research questions were addressed: Is monitoring attendance acceptable to students and staff? Is monitoring attendance practical for students and staff? Does monitoring attendance facilitate access to learning opportunities?

\section{Methods}

\section{Study setting}

The study was conducted by the Department of Obstetrics and Gynaecology, Trinity College Dublin (TCD), based at the Coombe Women and Infants University Hospital. The undergraduate program in OBGYN is completed over 8 weeks in the penultimate year of a 5-year degree course in medicine. There are four rotations during the academic year with $\sim 40$ students in each rotation. The program consists of a combination of clinical and classroom-based learning activities. Clinical activities consist of small group teaching sessions with medical staff on the wards, in operating theaters, on the delivery suite, and in outpatient clinics and also self-directed learning activities. Classroom-based activities consist of interactive lectures and small group tutorials. Hard copies of lecture notes or slides are only made available during the lecture, and lectures are not recorded. OBGYN is assessed as a single subject consisting of written assessments (single best answer questions and short answer questions) and practical assessments (objective structured clinical examination and a long case clinical examination). Students must pass the assessment in order to proceed to the final year of the degree course. Although students are strongly encouraged to attend, attendance is not mandatory as such.

\section{Study logbook}

During the 2011/2012 academic year, a student logbook was introduced to the undergraduate program in OBGYN. This was part of a separate prospective cohort study evaluating the relationship between student attendance and academic performance. ${ }^{1}$ Each student was required to complete a paper-based logbook during the rotation. The logbook was a 14-page paper booklet that listed every clinical and classroom-based activity that each student was expected to attend for each day of the rotation. Students were expected to attend 64 activities in total: 26 clinical activities and 38 classroom-based activities. Students verified their attendance at a particular activity by obtaining a signature from the tutor for that activity in their logbooks. The logbook was distributed on the first day of the rotation (with an explanatory session on its use), and then, students submitted their logbooks at the end of the rotation. The logbook did not contribute to the examination score. A sample page from the logbook is shown in Figure 1.

\section{Study design}

A cross-sectional survey of medical students who completed their OBGYN rotation over a full academic year (2011/2012) and staff who taught on that program was undertaken. This study grew from the previously described prospective cohort study evaluating the relationship between student attendance and academic performance. ${ }^{1}$ A survey was created to evaluate both student and staff experience of using the newly introduced logbook. The survey evaluated the opinion of students and staff about the acceptability, practicality, and effect on access to learning opportunities of the logbook. The student survey consisted of a combination of nine closed questions and an open-ended question allowing free-text comments. The staff survey consisted of a combination of six closed questions and an open-ended question allowing free-text comments. Similar questions were used for students and staff where appropriate in order to facilitate comparison between these groups. The study received Institutional Research Ethics Committee approval (Coombe Women \& Infants University Hospital: reference 13/2013).

\section{Participants}

All students who undertook their OBGYN rotation from September 2011 to June 2012 were invited to complete the student survey. Staff teaching regularly on that program (and therefore signing the logbooks) were identified and invited to complete the staff survey. Staff members "teach- 


\section{GYNECOLOGY - Coombe Hospital}

NAME:

DATES: From Monday $\quad$ to Friday

\begin{tabular}{|c|c|c|c|c|}
\hline Time & Ac tivity & Loc ation & Lecturer & Signature \\
\hline \multicolumn{5}{|c|}{ Monday } \\
\hline \multirow[t]{2}{*}{0830} & \multirow{2}{*}{$\begin{array}{l}\text { A/B - Theater } \\
\text { C/D - Emergency Room } \\
\text { E/F - History Taking }\end{array}$} & \multirow{2}{*}{$\begin{array}{l}\text { Theater } 2 \text { or } 3 \\
\text { Outpatients - Emergency Room } \\
\text { St Gerard's Ward }\end{array}$} & \multirow[b]{2}{*}{ Self Directed } & \\
\hline & & & & No signature required \\
\hline 1230 & Tutorial & Conference Center & & \\
\hline 1330 & $\begin{array}{l}\text { A/B/C - Gynecology Clinic } \\
\text { D/E/F - Gynecology Clinic }\end{array}$ & $\begin{array}{l}\text { Outpatients - Rooms 7\&8 } \\
\text { Outpatients - Rooms } 1 \& 2\end{array}$ & & \\
\hline 1630 & Tutorial & Conference Center & & \\
\hline \multicolumn{5}{|c|}{ Tuesday } \\
\hline 0830 & A/B/C/D/E/F - Theater & Theaters $2 \& 1$ & & \\
\hline 1230 & Tutorial & Conference Center & & \\
\hline 1445 & Tutorial & Conference Center & & \\
\hline \multicolumn{5}{|c|}{ Wednesday } \\
\hline 0830 & $\begin{array}{l}\text { C/D - Theater } \\
\text { E/F - Em ergency Room } \\
\text { A/B - History Taking }\end{array}$ & $\begin{array}{l}\text { Theater } 3 \\
\text { Outpatients - Emergency Room } \\
\text { St Gerard's Ward }\end{array}$ & \multirow{2}{*}{ Self Directed } & No sianature reouired \\
\hline 1400 & Tutorial & Conference Center & & \\
\hline 1500 & Tutorial & Conference Center & & \\
\hline \multicolumn{5}{|c|}{ Thur sday } \\
\hline 0830 & $\begin{array}{l}\text { E/F - Theater } \\
\text { A/B - Emergency Room } \\
\text { C/D - History taking }\end{array}$ & $\begin{array}{l}\text { Theater } 2 \\
\text { Outpatients - Emergency Room } \\
\text { St Gerard's Ward }\end{array}$ & \multirow{2}{*}{ Self Directed } & No signature required \\
\hline 1330 & $\begin{array}{l}\text { A/B/C - Gynecology Clinic } \\
\text { D/E/F - Gynecology Clinic }\end{array}$ & $\begin{array}{l}\text { Outpatients - Rooms } 1 \& 2 \\
\text { Outpatients - Rooms } 3 \& 4\end{array}$ & & \\
\hline 1600 & Tutorial & Conference Center & & \\
\hline \multicolumn{5}{|c|}{ Friday } \\
\hline 0830 & Reading & & Self Directed & No signature required \\
\hline 1230 & Tutorial & Conference Center & & \\
\hline 1400 & 'Round Up' Tutorial & Conference Center & & \\
\hline
\end{tabular}

Figure I A sample page from student logbook.

Notes: $A / B / C / D / E / F$ refers to individual students.

ing regularly on the program" were defined as those who gave at least one classroom-based tutorial and one clinical teaching session each week. No student or staff member was excluded. Students and staff were given the opportunity to opt out of the survey and indicated consent by participating in the survey.

\section{Data collection}

The survey was conducted online using a survey tool (Survey Monkey ${ }^{\circledR)}$. The responses to the survey were confidential. The survey was conducted 3 months after the end-of-year examination in OBGYN (September 2012) for both students and staff. The survey was conducted at this point because the assessment in OBGYN was complete for all students, allowing more authentic and reflective survey responses. An explanatory email requesting their participation accompanied the survey. Students and staff who failed to respond or failed to decline participation were sent two follow-up emails requesting their participation. Students and staff who failed to respond or failed to decline participation at this stage were not contacted further. Data relating to student demographics (sex, age, country of origin) and previous end-of-year failure were obtained from departmental records. Previous end-of-year failure refers to failure at any of the end-of-year examinations during the student's preceding 3 years on the medical course.

\section{Data analysis}

Descriptive statistics were used to describe responses to the quantitative questions on the survey. Not all respondents answered every question, and therefore, the number of responses to each question is stated. Responses to qualitative questions were analyzed using content analysis for themes. ATLAS.ti version 7 was used to assist content analysis. The profile of responders to the student survey was compared with nonresponders using the chi-squared test and Fisher's exact test. SPSS version 22 was used for statistical analysis. A significance level of 0.05 was used.

\section{Results \\ Student profile}

The response rate to the student survey was $87 \%(n=128 / 147)$ and staff survey was $80 \%(n=8 / 10)$. Table 1 provides a profile of student responders and nonresponders. Staff consisted of academic consultants $(n=4)$ and lecturers $(n=4)$ from the TCD Department of OBGYN with dedicated clinical and classroom-based teaching sessions and clinical teachers $(n=2)$ who taught students as part of their clinical sessions. 
Table I Student profile

\begin{tabular}{|c|c|c|c|}
\hline $\begin{array}{l}\text { Student } \\
\text { demographic }\end{array}$ & $\begin{array}{l}\text { Responders } \\
(n=I 28) \\
n(\%)\end{array}$ & $\begin{array}{l}\text { Nonresponders } \\
(n=19) \\
n(\%)\end{array}$ & $P$-value \\
\hline \multicolumn{4}{|l|}{ Sex } \\
\hline Male & $43(34)$ & $8(42)$ & 0.47 \\
\hline Female & $85(66)$ & II (58) & \\
\hline \multicolumn{4}{|l|}{ Age } \\
\hline 20-24 years & $100(78)$ & II (58) & 0.11 \\
\hline $25-29$ years & $21(16)$ & $5(26)$ & \\
\hline$\geq 30$ years & $7(6)$ & $3(16)$ & \\
\hline \multicolumn{4}{|l|}{ Country of origin } \\
\hline EU & $92(72)$ & II (58) & 0.43 \\
\hline North America & $16(12)$ & $3(16)$ & \\
\hline Asia/Africa & $20(16)$ & $5(26)$ & \\
\hline \multicolumn{4}{|c|}{ Previous end-of-year failure } \\
\hline No & $106(83)$ & $6(32)$ & $* 0.00$ \\
\hline Yes & $22(17)$ & $13(68)$ & \\
\hline
\end{tabular}

Notes: * indicates a statistically significant difference.

Abbreviation: EU, European Union.

\section{Student and staff survey - closed questions}

Table 2 summarizes the responses to the closed questions on the student and staff survey. Some questions only applied to either students or staff. Questions that were not applicable to a particular group are indicated by "N/A" within the relevant column in Table 2. There was no statistical difference between students and staff among the five common questions except whether attendance should contribute toward academic credit (with students divided and staff in favor). Approximately half of students ( $n=66 / 128,52 \%)$ encountered a difficulty obtaining a signature for their logbook at any one time point during the rotation. The reasons were as follows: the student forgot to ask the tutor at the time $(n=30 / 128,23 \%)$, the tutor was too busy to sign the logbook at the time $(n=30 / 128$, $23 \%)$, the student forgot the logbook $(n=29 / 128,23 \%)$, the

Table 2 Student and staff survey responses

\begin{tabular}{|c|c|c|c|c|}
\hline Survey question & Response & $\begin{array}{l}\text { Students } \\
(n=\mid 28), n(\%)\end{array}$ & $\begin{array}{l}\text { Staff } \\
(n=8), n(\%)\end{array}$ & $P$-value \\
\hline \multicolumn{5}{|l|}{ Acceptability of attendance monitoring } \\
\hline Was it acceptable to monitor attendance during the clinical & Yes & $107(84)$ & $8(100)$ & 0.46 \\
\hline \multirow[t]{2}{*}{ attachment? } & No & $16(12)$ & $0(0)$ & \\
\hline & No opinion & $5(4)$ & $0(0)$ & \\
\hline Do you think that attendance should be mandatory for medical & Yes & $95(74)$ & $7(88)$ & 0.69 \\
\hline \multirow[t]{2}{*}{ students during their clinical attachments? } & No & $31(24)$ & $I(12)$ & \\
\hline & No opinion & $2(2)$ & $0(0)$ & \\
\hline \multirow[t]{3}{*}{ Do you think that attendance should contribute to your overall mark? } & Yes & $51(40)$ & $7(88)$ & 0.03 \\
\hline & No & $73(57)$ & $I(I 2)$ & \\
\hline & No opinion & $4(3)$ & $0(0)$ & \\
\hline \multicolumn{5}{|l|}{ Practicality of attendance monitoring } \\
\hline Was completing (students) or signing (staff) the logbook an excessive & Yes & $27(2 I)$ & $0(0)$ & 0.15 \\
\hline burden on you? & No & $100(79)$ & $8(100)$ & \\
\hline Did you encounter any difficulties obtaining a signature for your & Yes & $66(52)$ & $\mathrm{N} / \mathrm{A}$ & \\
\hline logbook from any of the tutors? & No & $62(48)$ & N/A & \\
\hline Do you think that the present system (ie, the OBGYN logbook) & Yes & $94(73)$ & $6(76)$ & 0.64 \\
\hline \multirow[t]{2}{*}{ is working satisfactorily? } & No & $23(18)$ & $2(24)$ & \\
\hline & No opinion & II (9) & $0(0)$ & \\
\hline \multicolumn{5}{|l|}{ Effect on access to learning opportunities } \\
\hline Were there activities that you would not have attended had you & Yes & $80(63)$ & N/A & \\
\hline not been required to document your attendance in the logbook? & No & $48(37)$ & $\mathrm{N} / \mathrm{A}$ & \\
\hline Were there procedures that you would not have experienced had & Yes & $53(4 I)$ & N/A & \\
\hline \multirow[t]{2}{*}{ you not been required to document them in your logbook? } & No & $49(38)$ & $\mathrm{N} / \mathrm{A}$ & \\
\hline & Do not know & $26(20)$ & N/A & \\
\hline Did the logbook facilitate access to learning opportunities during the & Yes & $90(7 I)$ & N/A & \\
\hline rotation? & No & $37(29)$ & $\mathrm{N} / \mathrm{A}$ & \\
\hline Did signing the logbooks improve your interaction with medical & Yes & $\mathrm{N} / \mathrm{A}$ & $6(76)$ & \\
\hline \multirow[t]{2}{*}{ students? } & No & $\mathrm{N} / \mathrm{A}$ & $\mathrm{I}(\mathrm{I})$ & \\
\hline & Do not know & $\mathrm{N} / \mathrm{A}$ & $\mathrm{I}(\mathrm{I} 2)$ & \\
\hline
\end{tabular}

Abbreviations: N/A, not applicable; OBGYN, obstetrics and gynecology. 
Table 3 Selected free-text comments from students

\section{Positive comments}

- I think it is important that the logbook counts for something as a nod to showing a certain level of commitment to the course and ability to be punctual and adhere to a structure. I believe that these are really important traits as doctors. [Student 96]

- The logbook promotes attendance and facilitates learning. If fellow students do not attend an activity, it is easy to follow along with your peers and miss the activity too. The logbook helps to ensure that your peer group as a whole tend to be attending all the time and there is less temptation as such to miss any activities. [Student 64]

- I feel that the logbook worked really well, it encouraged full attendance and optimized learning opportunities. [Student 127]

- The portion for the labour ward was particularly useful for getting to see procedures as the staff thought we had to tick them all off and so made an effort to call us if there was a forceps etc. [Student 26]

- Logbooks encouraged people to attend the full rotation, which is only frustrating and a burden if attendance doesn't correlate with teaching and learning, which was never the case on OBGYN. [Student 126]

\section{Negative comments}

- I don't think attendance should be mandatory. Someone could have attended everything and learned absolutely nothing. The only way to prove you learned something on your clinical attachment is to do it in exams. [Student 6I]

- I don't think it should contribute to your mark. Surely the bare minimum that should be expected of all students is $100 \%$ attendance (or close). [Student 77]

- I think recording attendance at lectures is excessive but recording attendance at clinics and tutorials/small groups as well as procedures completed is completely appropriate. [Student 60]

- I felt the pressure to attend outpatient clinics and tutorials which were of no real benefit in order to get logbook signed. [Student 2I]

- On a few occasions there were too many students scheduled to be in the clinics. We all needed to be there, however, in order to get signed off. Perhaps if there were more flexibility with the logbooks that might not be an issue (eg, if clinic is full, take histories and get signed off on the wards). [Student 78]

Abbreviation: OBGYN, obstetrics and gynecology.

tutor was reluctant to sign the logbook $(\mathrm{n}=1 / 128,1 \%)$, or for other reasons $(n=15 / 128,12 \%)$. A majority of students $(n=80 / 128,63 \%)$ reported that they would not have attended certain activities had they not been required to document attendance. This was because the activity was perceived to be of little educational value ( $n=45 / 128,35 \%)$, because of personal commitments or illness $(n=38 / 128,30 \%)$, or for other reasons $(n=19 / 128,15 \%)$.

\section{Student survey - open-ended questions}

Of the 128 students who responded to the survey, 57 (45\%) provided free-text comments. Examples of free-text comments from students are provided in Table 3. The main positive themes arising from the content analysis were as follows:
Attendance should provide some academic contribution as it promotes important professional traits as a doctor. [Student 96]

The logbook promoted attendance through a peer effect ie, that students attended when their fellow students also attended. [Student 64]

By promoting attendance, the logbook facilitated access to learning opportunities. [Student 127]

The logbook was a good guide and structure for the rotation and helpful in completing important procedures.

[Student 26]

The logbook was successful as the educational activities were structured and beneficial. This is not always the case in other rotations and therefore logbooks may not be as successful in these settings. [Student 126]

The main negative themes arising from the content analysis were as follows:

Medical students should be able to decide the learning activities they wish to attend. Attendance does not necessarily equate to learning and the appropriate measure of achievement is the course assessment. [Student 61]

Attendance should not provide academic credit, as attending is the minimum that should be expected from medical students. [Student 77]

Obtaining tutor signatures for clinical activities was acceptable but for lectures was excessive and time-consuming.

[Student 60]

The logbook forced attendance at activities that were of little educational benefit. [Student 21]

The logbook should allow more flexibility with clinical activities. [Student 78]

\section{Staff survey - open-ended questions}

Of the eight staff members who responded to the survey, seven $(88 \%)$ provided free-text comments. The free-text comments from staff are provided in Table 4. The main themes arising from the content analysis were as follows:

The logbook was a good initiative particularly with a large number of students. [Staff members 4 and 6]

Providing academic credit for attendance would incentivize students. [Staff member 2]

The logbook was a good guide and structure for the rotation. [Staff member 1]

The logbook was not particularly effective. [Staff member 5] Some students requested signatures for previous sessions that they attended but had forgotten their logbook. How- 
ever, there was no way to verify whether they had actually

attended. [Staff member 7]

The logbook should allow more flexibility. [Staff member 3]

\section{Discussion}

\section{Principle findings}

Monitoring attendance was widely acceptable to students and staff. Most students and staff recommended that attendance should be mandatory during rotations. Almost all staff felt that attendance should contribute toward academic credit, but students were divided. Students and staff reported that the use of the logbook to record attendance with tutor signatures was a satisfactory system and not an excessive burden, although students questioned the need for recording attendance at every classroom-based activity. Most students felt that the logbook facilitated access to learning experiences during the rotation. Staff felt that that the process of signing logbooks improved their interaction with students.

Is monitoring attendance acceptable to students and staff? There is little published evidence on the attitudes of medical students or their teachers on attendance monitoring. Modern medical educators have recognized that learning activities must engage students better, ie, the use of active small group learning activities rather than passive large group learning activities. ${ }^{6-8}$ However, as medical schools convert to

Table 4 Free-text comments from staff

\section{Positive comments}

- Useful with such large numbers. [Staff member 4]

- Great improvement. Well done. [Staff member 6]

- Marks for full attendance would incentivise students. [Staff member 2]

- The logbook clearly defines the aims and objectives of the course and is a good guide to what the students should be doing on a day to day basis. [Staff member I]

\section{Negative comments}

- I don't think the logbook is particularly effective but I'm not sure what else you can do. [Staff member 5]

- I came across students who said that they forgotten to bring their logbook in their last lecture and said that they did attend. There was no way to check that for certainty. Maybe as a suggestion, the students could sign in before coming into the lecture hall. [Staff member 7]

- There is a lack of flexibility in some areas, for example theater attendance. Students often are just about to head off to a tutorial when a major case is coming into theater. I think in some cases if they can show the case was a good one and they were invited to stay it might be more beneficial than a tutorial. Also it seems to be out of fashion for the students to take the histories of patients and then follow into theater to see the procedure. [Staff member 3] a "flipped-classroom" approach, evidence is emerging that this approach does not necessarily guarantee attendance. ${ }^{9,10}$ Consequently, medical schools continue to be challenged to monitor the attendance of their students, and in this context, acceptability of attendance monitoring is a key issue. In this study, the learning activities used on the OBGYN program were student centered using active learning methods. The majority of students and staff reported that monitoring attendance was acceptable and, in fact, stated that attendance should be mandatory. The attitude of staff was unsurprising, but the enthusiastic embracement of attendance monitoring and mandatory attendance by students was unexpected. This can be explained by the fact that students indicated they valued attendance at "educationally beneficial" activities and that they considered their learning experiences during this program as beneficial. In summary, monitoring attendance is acceptable to students and staff, but for students, this may be dependent on their perception of the educational benefit of the learning activities.

Is monitoring attendance practical for students and staff? Higher education institutions have developed a variety of manual and electronic systems for monitoring student attendance. ${ }^{11}$ Manual systems of monitoring attendance consist of student sign-in sheets, student roll calls, or student logbooks using tutor signatures. Because of the administrative difficulties with manual systems, electronic systems for monitoring attendance have evolved. Electronic systems may identify students through a unique device (eg, identification card) or biometrics. ${ }^{12-17}$ Fingerprints are often used as the identifying biometric, although others are also used, including the eyes, face, ear shape, and voice recognition. However, many electronic methods require a fixed location and are not practical for use in clinical settings at present. Although student logbooks are generally used to record clinical experiences without the need for verification signatures from tutors, some have raised concerns over the accuracy of this self-reported data. ${ }^{18,19}$ To ensure accuracy of logbook entries in this study, a tutor's signature was required for each activity. Despite this rather onerous undertaking, it was reassuring that the majority of students and staff did not regard completing the logbooks as an excessive burden. The major burden for students obtaining staff signatures appeared to be for classroom-based activities, which were too time consuming. It may be that the focus of the logbook should be on recording of clinical activities with the use of more efficient electronic identification cards for classroom-based activities. A particular dilemma identified by staff was students requesting signatures at later dates for activities they had apparently attended. A possible solution is 
for staff to adopt a "zero tolerance" policy. In summary, the use of a paper-based logbook with verification signatures from tutors is a practical method of monitoring student attendance.

Does monitoring attendance facilitate access to learning opportunities? Learning in clinical environments differs from classroom-based environments as it requires students to engage with staff within busy, unfamiliar hospital working environments. ${ }^{20}$ The majority of students reported that the use of the logbook facilitated their access to learning opportunities. From a student perspective, an explanation was the requirement to obtain tutor signatures, which meant that students had to push themselves to verbally interact with clinical staff. Staff themselves also noted this improved interaction. From a staff perspective, an explanation was the requirement to provide signatures, which created an onus to provide learning experiences to students. The majority of students reported that the use of the logbook promoted attendance. An interesting student comment was that good attendance in general during the rotation had a "domino" effect on other students, ie, students were more likely to attend when they knew that the other students were attending. Medical educators often view attendance at the "individual" student level, but this study highlights the importance of the "peer effect" of good attendance in general. One-third of students reported that they attended activities that they would not have otherwise attended as they perceived these activities would be of little educational value. However, students may not be best placed to make these judgments in advance of learning activities, particularly as the evidence for "learning style based instruction" is limited. ${ }^{21-23}$ In summary, the use of the logbook to record attendance facilitated the provision of learning opportunities and interaction between students and staff.

\section{Strengths}

In contrast to previous studies examining medical student attendance, this study evaluated attendance across both clinical and classroom-based activities. The inclusion of both students and staff provided a broad overview of their experiences with monitoring attendance. The use of the same questions for students and staff allowed a direct comparison between these groups. The validity of the findings was further heightened by the high response rate to the surveys. The diverse demographic profile of the student population supports the generalizability of these findings.

\section{Limitations}

Although the overall response rate was high, nonresponders were more likely to have a previous end-of-year failure.
Therefore, the experiences of an important group of students may not have been adequately represented in the survey. The survey only included staff that were an integral part of the teaching program, limiting the sample size. The survey was distributed 3 months after the last rotation was concluded, and the final marks in OBGYN were published. This time interval was chosen to ensure that students felt free to comment openly on their attitudes and experiences. However, this interval may have contributed to an element of recall bias. The fact is that the study was limited to a single center and a single discipline may limit the wider generalizability of the findings. The very structured nature of the OBGYN rotation may have significantly contributed to the success of the logbook, and it may not be as useful in clinical rotations with different formats.

\section{Implications for academic practice and future research}

Medical student attendance continues to pose challenges for medical educators, particularly in the face of new learning technologies. ${ }^{24}$ The use of electronic attendance monitoring within medical education would be readily applicable to classroom-based activities but less so with clinical activities and would require further research. This study provides medical schools with an acceptable and practical method of monitoring attendance within diverse learning environments. However, some aspects of this approach were labor intensive, and alternative electronic approaches for monitoring aspects of attendance should be evaluated. In addition, medical educators should explore student attendance at an overall class level (and not only at the individual student level) in order to evaluate the effect of student attendance patterns on other students and whether there is a "critical mass" attendance threshold within a class.

\section{Conclusion}

The survey showed that the use of a paper-based logbook to record medical student attendance with tutor signatures across all clinical and classroom-based learning activities was acceptable and practical for students and staff and was felt to facilitate access to learning opportunities. The study provides medical educators with evidence to support monitoring of attendance within clinical rotations.

\section{Acknowledgments}

We would like to acknowledge the immense contribution of the fourth-year medical students and staff members at TCD who completed the student logbooks and survey. We are 
grateful to Ms Cristina Boccado (Executive Officer, TCD) who collated the logbooks following each rotation. We would like to acknowledge the support of this study by Professor Patricia Crowley (Professor of Obstetrics and Gynaecology, TCD) and Professor Martina Hennessy (Director of Undergraduate Teaching, TCD).

\section{Author contributions}

RPD and DJM conceived the study concept and design. RPD coordinated and conducted the study, analyzed and interpreted study data, and drafted the manuscript. DJM helped with analysis and interpretation of study data and provided critical revision of the manuscript for important intellectual content. Both authors read and approved the final manuscript. All authors contributed toward data analysis, drafting and critically revising the paper and agree to be accountable for all aspects of the work.

\section{Disclosure}

The authors report no conflicts of interest in this work.

\section{References}

1. Deane RP, Murphy DJ. Student attendance and academic performance in undergraduate obstetrics/gynecology clinical rotations. JAMA. 2013;310(21):2282.

2. Hamdy H, Prasad K, Anderson MB, et al. BEME systematic review: predictive values of measurements obtained in medical schools and future performance in medical practice. Med Teach. 2006;28(2): 103-116.

3. Tomorrow's Doctors [webpage on the Internet]. General Medical Council; 2009 [cited October 15, 2015]. Available from: http://www .gmc-uk.org/Tomorrow_s_Doctors_1214.pdf_48905759.pdf. Accessed February 16, 2016

4. Medical Students: Professional Values and Fitness to Practise [webpage on the Internet]. General Medical Council; 2009 [cited October 15, 2015]. Available from: http://www.gmc-uk.org/Medical_students professional_values_and_fitness_to_practise_1114.pdf_48905163.pdf. Accessed February 16, 2016

5. Smith LB. Medical school and on-line learning: does optional attendance create absentee doctors? Med Educ. 2012;46(2):137-138.

6. Kanter SL. To be there or not to be there: is attendance really the question? Acad Med. 2012;87(6):679.

7. Greenberg L. More about medical students' attendance at lectures. Acad Med. 2013;88(2):149.
8. Kalmey JK. Stop wasting classroom time: embrace the podcast and use the "lecture" to enhance learning. Acad Med. 2013;88(8):1054.

9. White C, Bradley E, Martindale J, et al. Why are medical students "checking out" of active learning in a new curriculum? Med Educ. 2014;48(3):315-324.

10. White C, McCollum M, Bradley E, et al. Challenges to engaging medical students in a flipped classroom model. Med Sci Educ. 2015; 25(3):219-222.

11. Bowen E, Price T, Lloyd S, Thomas S. Improving the quantity and quality of attendance data to enhance student retention. J Furth High Educ. 2005;29(4):375-385.

12. Onyx Student Attendance Monitoring System [webpage on the Internet]. Telepen; [cited October 15, 2015]. Available from: http://telepen.co.uk/ student-attendance-system/. Accessed February 16, 2016

13. Kumar S, Walia E. Analysis of various biometric techniques. Int J Comput Sci Inf Technol. 2011;2(4):1595-1597.

14. Taxila P. Development of academic attendance monitoring system using fingerprint identification. IJCSNS. 2009;9(5):164.

15. Shoewu O, Idowu OA. Development of attendance management system using biometrics. Pac J Sci Technol. 2012;13(1):300-307.

16. Tiwari A, Tiwari A, Ade N, Sheikh S, Patel N, Khan A. Optimized design of Student Attendance System Using RFID. International Institute of Engineers; 2014. [cited December 27, 2015]. Available from: http:// iieng.org/images/proceedings_pdf/6246E0114018.pdf. Accessed February 16, 2016.

17. Meor Said MA, Misran MH, Othman MA, et al. Biometric attendance. IEEE; 2014:258-263. [cited December 27, 2015]. Available from: http:// ieexplore.ieee.org/lpdocs/epic03/wrapper.htm?arnumber=6936516. Accessed February 16, 2016.

18. Raghoebar-Krieger HMJ, Sleijfer D, Bender W, Stewart RE, Popping R. The reliability of logbook data of medical students: an estimation of interobserver agreement, sensitivity and specificity. Med Educ. 2001;35(7):624-631.

19. Denton GD, Hoang T, Prince L, Moores L, Durning S. Accuracy of medical student electronic logbook problem list entry. Teach Learn Med. 2007;19(4):347-351.

20. Dyrbye LN, Thomas MR, Shanafelt TD. Medical student distress: causes, consequences, and proposed solutions. Mayo Clin Proc. 2005; 80(12):1613-1622.

21. BinSaeed AA, Al-Otaibi MS, Al-Ziyadi HG, Babsail AMA, Shaik SA. Association between student absenteeism at a medical college and their academic grades. J Int Assoc Med Sci Educ. 2009;19(4):155-159.

22. Rohrer D, Pashler H. Learning styles: where's the evidence? Med Educ. 2012;46(7):634-635.

23. Feeley AM, Biggerstaff DL. Exam success at undergraduate and graduate-entry medical schools: is learning style or learning approach more important? A critical review exploring links between academic success, learning styles, and learning approaches among school-leaver entry ("traditional") and graduate-entry ("nontraditional") medical students. Teach Learn Med. 2015;27(3):237-244.

24. Doherty I, Sharma N, Harbutt D. Contemporary and future eLearning trends in medical education. Med Teach. 2015;37(1):1-3.
Advances in Medical Education and Practice

\section{Publish your work in this journal}

Advances in Medical Education and Practice is an international, peerreviewed, open access journal that aims to present and publish research on Medical Education covering medical, dental, nursing and allied health care professional education. The journal covers undergraduate education, postgraduate training and continuing medical education

\section{Dovepress}

including emerging trends and innovative models linking education, research, and health care services. The manuscript management system is completely online and includes a very quick and fair peer-review system. Visit http://www.dovepress.com/testimonials.php to read real quotes from published authors. 